Copyright @ 2017 Cognizant Communication Corporation

http://dx.doi.org/10.3727/154427317X14964473293699

TIME 194 accepted for publication in Tourism in Marine Environments

\title{
SEAL WATCHING: AN INVESTIGATION OF CODES OF CONDUCT
}

Elin Lilja Öqvist, Zoological Department, Stockholm University, Sweden

Sandra M. Granquist, Zoological Department, Stockholm University, Sweden; The Icelandic Seal Center, Iceland; Marine and Freshwater Research Institute, Iceland

Georgette Leah Burns, Environmental Futures Research Institute, and Griffith School of Environment, Griffith University, Australia; Department of Rural Tourism, Hólar University College, Iceland

Anders Angerbjörn, Zoological Department, Stockholm University, Sweden

Corresponding author: Sandra Granquist, The Icelandic Seal Center, Brekkugata 2, 530 Hvammstangi, Iceland. e-mail: sandra@ veidimal.is, ph: +345-4512345 


\begin{abstract}
Seal watching as a form of wildlife tourism is becoming increasingly popular worldwide. Behavioral changes caused by the presence of tourists could lead to negative consequences for seal welfare and may affect reproduction and survival. Therefore, managing seal watching activities to ensure future protection and conservation is important. Codes of conduct or guidelines for how to behave around animals are one way to regulate wildlife watching and are often easier and quicker to implement than laws. Codes explaining the consequences for wildlife if the code is not followed appeal to the moral obligation of tourists and thereby increase incentives to act appropriately. This study focused on analyzing the content of codes of conducts for seal watching. Codes of conducts $(n=33)$ accessible on the internet during the time of study were analysed. Results show that in many areas where seal watching occurs there are no regulations or guidelines. The content and detail of the codes varied and the information was often insufficient to offer adequate protection of seals. Few of the codes were developed in cooperation with scientists or stated that the content was based on research. Further, a majority of the codes did not explain the consequences for wildlife if the code was not followed.

More research on seals and the tourists watching them is needed to better understand the effects of tourism and how disturbance could be minimised. Meanwhile, developing an international code of conduct (with local additions) built on existing knowledge in the field, could be one option to increase protection and ensure conservation of these animals. The results presented in this paper could assist the development of such a code of conduct.
\end{abstract}

Keywords: Tourism, seals, wildlife, management, codes of conduct, conservation, disturbance, mammals. 


\section{Introduction}

Interest in wildlife tourism is increasing and disturbance of wildlife due to tourism activities can have negative impact on wild animals. Hence, there is a need to develop and implement effective management plans and actions. Due to the rapid growth of wildlife tourism, legislation often does not keep pace with the development of activities (Garrod \& Fennell, 2004). One way to protect wildlife until legislation is in place is to implement codes of conduct with guidelines on how people should behave during wildlife watching to minimize disturbance to animals (Mason \& Mowforth, 1996). Codes of conduct are used to manage tourist activities with a variety of different species, including marine wildlife such as whale sharks (Quiros, 2007), whales (Garrod \& Fennell, 2004) and seals (Strong \& Morris, 2010). Although codes of conduct are used worldwide to reduce disturbance to seals, a comprehensive investigation of codes pertaining to seals has been absent from the literature on wildlife tourism.

In this paper, we investigate existing codes of conduct for seal watching globally. The geographical distribution of the codes of conduct, as well as the setting and content of the codes is analyzed and evaluated to understand the extent to which seal tourism is managed by these guidelines, and assess scientific robustness of the information provided. The content is also analyzed to define general and species- or site specific factors that the different codes take into consideration. Finally, the development of an international code of conduct for pinniped watching is suggested.

\section{Background}

\section{Marine Wildlife tourism}

The popularity of a diverse range of wildlife tourism activities where humans interact with animals in their natural habitat is increasing (Dobson, 2008; Lemelin \& Dyck, 2008). In marine settings, wildlife tourism includes consumptive forms such as fishing, hunting, and non-consumptive forms such as observing wildlife from land and sea, as well as swimming, snorkeling and scuba diving with wild animals. Increased interest in seals watching might be linked to the large growth in other marine tourism activities worldwide, such as whale watching (Cater, 2010). 
Interacting with, and proximity to, animals is often linked to human satisfaction during wildlife tourism experiences (Cong et al., 2014; Valentine et al., 2004; Zeigler et al., 2012). Close interactions can however lead to negative consequences for both animals and humans (Burns \& Howard 2003). For wildlife, increases in the level of stress hormones due to human disturbance are common (Creel et al., 2002) and prolonged periods of stress could potentially lead to reduced rearing success and decreased overall fitness (Ellenberg et al., 2007; Müllner, 2004). Behavioral changes due to tourist disturbance have been noted in a range of different species, and include avoidance of highly touristed areas (Henry \& Hammill, 2001; Lundquist et al., 2013), changes in resting and feeding patterns (Christiansen et al., 2013a; King \& Heinen, 2004;), increased erratic movement (Lusseau, 2006), increased vigilance (Borkowski et al., 2006; Granquist \& Sigurjonsdottir, 2014) and habituation (Burns, 2015a). Changes in natural behavior can affect energy budgets of the animals if more time is used for high energy consuming behaviors such as fleeing or interacting rather than resting or feeding (Christiansen et al., 2013b; Fitzpatrick et al., 2011; King \& Heinen, 2004). Further, disturbance has been shown to prevent animals from engaging in essential behavior such as nursing their offspring (Kovacs \& Innes, 1990).

Provisioning (feeding) of marine wildlife for the purposes of tourism has led to increased population densities and interference competitions (Semeniuk \& Rothley, 2008), physiological indications of impoverished health (Semeniuk \& Rothley, 2009) and increased risk of boat strike and entanglement of the animals (Donaldson et al., 2010). Long- term effects of tourism on wildlife are difficult to determine due to the complexity of both the tourism activities and the animal behaviour (Bejder et al., 2006), with many authors concluding that further research is required (e.g., Maljovic \& Côte, 2011). Awareness of indications of disturbance due to tourism and taking action to minimize negative short-term effects are important to prevent irreversible, long-term damage.

\section{Sustainable wildlife tourism}

Since increases in the number of tourists travelling to experience wildlife has potential to negatively impact on nature, effective management is required for wildlife tourism to be sustainable (Davenport \& Davenport, 2006; Gössling, 1999; Moore \& 
Rodger, 2010). Although disturbance due to tourism can have negative effects on wildlife, tourism might also be positive for conservation (Ballantyne et al., 2011; Higginbottom \& Tribe, 2004). An increasing market for wildlife tourism also has potential benefits in terms of employment and economy of local communities (Burns, 2004; Lindsey et al., 2013; Osano et al., 2013) and increased revenues from wildlife tourism could raise local interest and awareness of conservational issues (Lindsey et al., 2005; Sekhar, 2003). Wildlife tourism experiences can also assist to motivate and educate tourists about conservation and environmental issues (Ballantyne et al., 2009; Orams, 1997).

\section{Codes of conduct}

Codes of conduct can be effective in reducing disturbance to wildlife even though they rarely completely eliminate negative impacts (Duprey et al., 2008; Quiros, 2007). Whether tourists accept and follow codes depends on numerous human factors, such as perceptions of species and economic aspects, but can also be affected by the way the guidelines are presented (Cole, 2007; Sirakaya, 1997).

A code of conduct may contain guidelimes stated without explanation of their function, or guidelines that include explanation of the possible consequences of noncompliance (Granquist \& Nilsson, 2016). The latter allude to the moral obligation of the tourist by explaining the consequences for wildlife if the guidelines are not followed. This can increase tourist incentives to minimize disturbance, thus benefiting the wildlife (Burns et al., 2011; Granquist \& Nilsson, 2016).

Encounters with animals can be an emotional experience for tourists and create a feeling of being part of nature (Curtin, 2009). Adding educational value to the experience of the tourist could also enhance the wildlife experience (Lück, 2003; Ziegler et al., 2012). Zoological gardens in particular, in their role as "biological conservation educator" (Patrick \& Tunnicliffe, 2013, p.37) lead the way in this type of edutainment which aims to blend information and education with entertainment for the purpose of increasing visitor enjoyment and knowledge. In combination with relevant information on wildlife and background regarding conservational issues, codes facilitating both edutainment and emotional connections could increase ethical 
awareness and motivation to protect nature (Ballantyne et al., 2009; Burns et al., 2011; Fennell 2012).

\section{Seals and tourism}

Pinnipeds, aquatic mammals of the suborder pinnipedia, include all species of seals, sea lions and walruses. Pinnipeds received increased interest from tourists in the $20^{\text {th }}$ Century (Kirkwood et al., 2003) and their continued popularity might be attributed to them often occurring in large groups and being accessible and predictable in behavior (Le Boeuf \& Campagna, 2013).

Many studies have concluded that tourists can have major impact on pinnipeds. Seals react to factors like sound and movement in the environment (Granquist \& Sigurjónsdóttir, 2014) and an underestimated source of disturbance could be scent since seals respond to different scent sources (Kowalewsky et a1. 2006).

Kovacs \& Innes (1990) noted that tourist presence during the pupping season of harp seals (Pagophilus groenlandicus) in the Gulf of St. Lawrence could be harmful to seal pups, with increasing anxiety and activity of the mother and decreasing time for nursing. Human presence often increases seal vigilance (Granquist \& Sigurjónsdóttir, 2014; Orsini et al. 2006) and causes them to flush into the water as a consequence of disturbance (Andersen et al., 2012; Osinga et al., 2012). Mattlin (1978) noted that in colonies of New Zealand fur seals (Arctocephalus forsteri) human disturbance caused panic and lead to stampedes resulting in young individuals being trampled to death. However, Granquist \& Sigurjónsdóttir (2014) showed that calm tourist behavior during land based seal watching led to lower proportions of vigilance in harbour seals (Phoca vitulina) in Iceland compared to when visitors behaved in a more active way. Similarly, Cassini (2001) showed that visitors behaving calmly during land based viewing disturbed South American fur seals less than loud and active visitors. Possibilities of minimising impact due to boat based seal watching by modifying the boat trips has also frequently been discussed in the literature; for example by increasing distance between the boat and the animals (Henry \& Hammill, 2001; Jansen et al., 2010; Johnson \& Acevedo-Gutiérrez, 2007;) and adjusting the boat speed (Henry \& Hammill, 2001; Hoover-Miller et al., 2013). Hence, to ensure minimal disturbance of individual 
animals, pinniped populations and species, tourist activities in the vicinity of pinnipeds should be regulated.

Implementing codes of conduct is a suitable way to manage disturbance of marine mammals (Duprey et al., 2008; Quiros, 2007). However, many of the codes of conduct developed for marine mammal tourism refer only to whale watching, probably due to the fact that whale watching is a more developed tourism industry than pinniped watching (Carlson, 2001). According to Kirkwood et al. (2003) information available to people on how to behave during pinniped watching is insufficient and more emphasis needs to be placed on developing, implementing and encouraging people to comply with codes of conduct to ensure a sustainable future for these animals. However, although interest in pinniped watching has grown and the number of entrepreneurs offering pinniped watching has increased in many areas of the world (e.g., Granquist and Sigurjónsdóttir, 2014; Hoover-Miller et al., 2013), the call for improvement in pinniped watching codes of conduct by Kirkwood et al., (2003) twelve years ago has remained largely unanswered. As an example, no universal international code of conduct for pinniped watching exists and an analysis of existing codes of conducts developed for pinniped watching is also lacking.

\section{Materials and Methods}

Codes of conduct and guidelines regarding pinniped tourism worldwide were collected for analysis and comparison. The research was conducted using Google (www.google.com) to access internet documents between 22 January and 10 February 2014. Phrases used in the Google search included, but were not limited to: Code of conduct seal watching, Code of conduct pinnipeds, Code of conduct marine wildlife, Guidelines seal watching, Guidelines marine mammals, Wildlife watching seals. Other phrases used in the search included synonyms and phrases similar to those mentioned above. The terms "code of conduct" and "guidelines" reflect a difference in terminology rather than content, hence both types were included.

For the parameters of this study, a code of conduct was defined as a text or document containing recommendations or regulations for safe practice of an activity involving humans approaching pinnipeds in non-captive settings. Codes aimed for the general public or tourists specifically were included, as well as codes for tour operators. 
Regulatory codes of conduct were included with the criterion that they were aimed at a general audience. Marine mammal acts and law texts were therefore excluded from the study. Codes focusing broadly on marine wildlife or marine mammals tended to contain recommendations primarily relevant for cetaceans. Therefore, only documents specific to pinnipeds, or general for marine wildlife with additions referring specifically to pinnipeds, were included. In four cases numerous documents developed by the same institution for one area were found. Since the content was almost identical, these were defined as one code of conduct. All statistical analyses are based on analyses of number of codes in different groupings $\left(\chi^{2}\right.$-statistics).

Categories used in the analysis were partly derived from the study of Garrod and Fennell (2004) who conducted a similar study on codes of conduct for whale watching. In total, 13 relevant factors were determined and used during the analysis. Eight of these factors considered the setting and general information about the codes and five factors were used to analyze and compare the content of the codes (Table 1). These factors were used to find similarities and differences between the codes and to determine if any general patterns could be determined.

\section{Table 1 here}

\section{Results}

\section{Codes of conduct - settings}

In total 33 codes of conduct for pinniped watching were found. Of these, 39\% were from Europe, 36\% from North America, and 18\% from Australia and New Zealand. Only one code (3\%) was found for Africa and one (3\%) for Antarctica. No codes were found for Asia or South America. The codes were primarily developed by governments (58\%) and non-government organisations (27\%), but it is interesting to note that $15 \%$ came from industry or individual companies $\left(\chi^{2}=9.45, \mathrm{p}<0.01\right) .24 \%$ of the codes stated that they had been developed in cooperation with researchers or specialists; but most $\left(76 \%, \chi^{2}=8.92, \mathrm{p}<0.01\right)$ did not contain any information regarding the background of the codes. More than half of the codes did not state that they were based on laws (55\%). $30 \%$ were completely regulatory and $15 \%$ were partly regulatory, 
stating that one or a few of the guidelines were directly based on laws. The regulatory codes were mostly from the Southern hemisphere.

Twenty seven percent of the codes were written for marine mammals with additions focusing on pinnipeds and $21 \%$ were written for marine wildlife in general, but contained additions on pinnipeds. Pinnipeds in general were the focus animal group in $39 \%$ of the codes, but only $12 \%$ (four codes) considered specific species of pinnipeds. The species-specific codes focused on threatened species of pinnipeds or locations where tourism was directed to only one species. These were Mediterranean monk seal (Monachus monachus) in Croatia, walrus (Odobenus rosmarus) in Svalbard, elephant seal (Mirounga angustirostris) in California and Hawaiian monk seal (Neomonachus schauinslandi) in Hawaii.

Tour operators were specifically addressed in $21 \%$ of the codes, and $12 \%$ addressed both tour operators and tourists. Most of the codes $\left(48 \% ; \chi^{2}=10.3, p<0.05\right)$ addressed the general public, including tourists, while $18 \%$ were aimed at tourists or visitors only. In total, 27 of the 33 of the codes mentioned boat-based pinniped watching $\left(\chi^{2}=13.4, p<0.001\right)$ and of these $45 \%$ focused on both boat and land-based watching, while $36 \%$ of the codes focused on boat-based watching only.

Codes not explaining the reason or background for the code $(55 \%)$, were more common than those with explanation $\left(30 \% ; \chi^{2}=7.82, \mathrm{p}<0.05\right)$. Some codes $(15 \%)$ were classified as partly explanatory where the background of one, or a few guidelines were explained further. The more explanatory codes were developed by governments in $70 \%$ of the cases $\left(\chi^{2}=5.28, p<0.05\right)$, and most were aimed at the general public $(50 \%)$ or tour operators (30\%). However, only one of the eight codes built on research was explanatory ( $13 \%$; no significant difference).

\section{Codes of conduct - content}

Codes that contained recommendations for minimum distance from the animals were common both for boat-based pinniped watching (85\%) and those for land-based watching $\left(64 \% ; \chi^{2}=2.01, \mathrm{p}>0.05\right)$. The typical recommendation for minimum distance regarding boat-based watching was $40-100$ meters (60\% of the codes) whereas for land- 
based viewing, the typical recommendation was 5-30 meters (41\% of those codes) and in general at a shorter distance $\left(\chi^{2}=6.18, \mathrm{p}<0.05\right)$ (Figure 1).

\section{Figure 1 here}

Recommendations for maximum time in the vicinity of pinnipeds varied between ten and 60 minutes. In codes aimed at boat-based watching, 52\% recommended time limitations and the most common recommendations for maximum viewing time were in the range of 20-30 minutes $(26 \%)$ or $10-15$ minutes (22\%). One code $(4 \%)$ limited maximum time to 60 minutes. For land based watching, such recommendations were not as common $\left(14 \%, \chi^{2}=6.79, \mathrm{p}<0.05\right)$ with recommendations in the range of 20-30 minutes (Figure 2).

\section{Figure 2 here}

Swimming with pinnipeds was allowed in the majority of codes for Oceania (five out of six), but otherwise swimming with pinnipeds was discouraged (48\%) or not mentioned $(36 \%)$. Feeding was strictly forbidden or not recommended in $61 \%$ of the codes, but never encouraged $\left(\chi^{2}=18.7, p<0.001\right)$. Touching was forbidden or not recommended in $58 \%$ of the codes, while other codes did not mention these practices. Touching was not openly encouraged or permitted in any of the codes $\left(\chi^{2}=17.6\right.$, $\mathrm{p}<0.001$ ). The description of touching as a dangerous practice (e.g., because pinnipeds might bite or spread disease) was present in most codes. Seventy percent of the codes contained recommendations on reducing noise levels when approaching pinnipeds $\left(\chi^{2}=5.28, p<0.05\right)$. Recommendations on noise levels for boats were often related to engine sounds, while codes aiming at land-based pinniped watching focused on encouraging tourists to lower their voice (Figure 3).

\section{Figure 3 here}

Sixty four percent of all codes contained requests to be aware of pinniped behavior and act accordingly if disturbance was noticed. However, only $67 \%$ of the 
codes requesting awareness of pinniped behavior provided examples of how the animals behaved if disturbed.

Special recommendations for sensitive periods of time were present in $42 \%$ of the codes $\left(\chi^{2}=0.85, \mathrm{p}>0.05\right)$. The sensitive periods mentioned were mostly related to reproductive events such as breeding, pupping and nursing, and some codes defined when during the year these events occur. Only two codes mentioned molting as a sensitive event, and these concerned harbour seals (Phoca vitulina) and grey seals (Halichoerus grypus) in Scotland and Iceland (Figure 4).

Area-specific recommendations or regulations were found in $39 \%$ of the codes (Figure $4 ; \chi^{2}=1.60, p>0.05$ ) and included statements recommending extra caution within areas where pinnipeds were more sensitive to disturbance. The sensitive areas mentioned included, for example, pupping beaches or breeding islands, as well as sanctuaries for specific species.

\section{Figure 4 here}

\section{Discussion}

\section{Codes of conduct- settings}

Thirty three codes of conduct regarding watching of pinnipeds were analyzed and compared in this study. The vast majority of codes found were from the northern hemisphere, especially from North America and Europe. The number of codes found for each region does not reflect the distribution of pinniped watching sites in the world. For example, although pinniped watching has been noted as a common practice in Australia, New Zealand, South Africa and parts of South America (Kirkwood et al., 2003), very few codes were found for these locations. Management strategies for pinniped-watching differ between different locations, and in the southern hemisphere many activities are regulated either by fencing or licensing of tour operators rather than with guidelines (Kirkwood et al., 2003). It is likely that more codes exist and, we hope our paper will encourage agencies and tourist operators to make their codes publicly available via the internet.

The large percentage of codes aimed at the general public (48\%) is probably a result of most codes found being developed for heavily populated areas (the USA and 
UK especially) where local people reside in the vicinity of pinnipeds. Governments were responsible for developing $58 \%$ of the codes and could be the most neutral source of a code, since the tourism industry, NGOs (Non-Governmental Organisations) and scientists might be more biased in representing their own interests in developing a code (Granquist \& Nilsson, 2016). However, to successfully cover all aspects of pinniped watching operations, developing a code suitable for use that minimizes disturbance to pinnipeds requires the cooperation of all stakeholders involved (Granquist \& Nilsson, 2013).

Incorporating knowledge derived from academic research while developing a code of conduct is an important issue. Only $24 \%$ of the codes stated that they were based on research or developed in cooperation with conservation specialists (Table 1). However, more of the codes may have been based on research without acknowledgement of this within the code or on the publication site. Some of the codes were similar in content and it is hence possible that some were based upon already existing codes of conduct for different locations. Without supporting evidence from research the code loses some of its validity, and the results of this investigation indicate that at least some codes were developed without the cooperation of a specialist in the field. The apparent lack of research evidence in code building might be due to an absence of knowledge regarding the conditions under which human activities may impact pinnipeds. More research on tourists and pinniped interactions is required to develop codes that can aid in minimizing disturbance at individual locations and worldwide.

Only $30 \%$ of the codes found in this study explain why guidelines should be followed and the potential consequences for wildlife if they are not. People engaging in wildlife tourism are generally keen to minimize disturbance to wildlife (Ballantyne et al., 2009; Burns et al., 2011) and hence codes should provide information on how, and why, to minimize wildlife disturbance (Granquist \& Nilsson, 2016).

\section{Codes of conduct - content}

More codes were found for boat-based pinniped watching (36\%) than for landbased watching (18\%). Andersen et al., (2012) show that harbour seals react more strongly to approaching boats than to pedestrians, while Boren et al., (2002) found that 
New Zealand fur seals reacted more strongly to approach from land than from sea. Therefore, separate guidelines for boat-based and for land-based watching are important. Many studies have concluded that closer approaches generally elicit stronger responses in pinnipeds (e.g., Boren et al., 2002; Jansen et al. 2010; Shaughnessy et al., 2008; Strong \& Morris, 2010) and approach distance is therefore an important variable to control. However, a study by Johnson \& Acevedo-Gutiérrez (2007) on buffer zones in the north west of the United States showed that harbour seals did not react to passing boats within the minimum approach distance (100 meters), although stopping boats and kayaks could cause disturbance at greater distances. The proper distance for reducing disturbance seems to differ with species and situation (Boren et al., 2002; Cassini, 2001; Osinga et al., 2012); hence, it is difficult to standardize a minimum approach distance applicable for all pinnipeds and all locations.

Recommendations for maximum time allowance were more common for boatbased watching than for land-based watching (Figure 2). These time limits are difficult to evaluate since very few studies exist on cumulative effects on pinnipeds by tourists. A larger number of tourists may have greater impact on the pinnipeds (Granquist \& Sigurjonsdottir, 2014) and therefore the total level of disturbance might increase if each tourist stays for a longer time. The presence of tourists often causes animals to engage in more active behaviors and prolonged exposure increases the risks of interfering with the animals' energy budget (Christiansen et al., 2013a; Fitzpatrick et al., 2011; King \& Heinen, 2004). Time limitations can therefore be an effective measure to control the number of people on site at one time and hence diminish the risk of reducing resting time for the pinnipeds (Granquist \& Sigurjonsdottir 2014). Codes should preferably present limits regarding distance and time where disturbance becomes noticeable; although it should be noted that disturbance can also be caused outside these limits. These limits should be dependent on the species involved and topography of the area and should be monitored and re-evaluated at regular intervals after implementation to determine if the limits effectively minimize disturbance.

Sixty four percent of the codes ( 21 codes) provided recommendations on how to act if a pinniped showed signs of disturbance. For recommendations on disturbed behavior to be effective, examples of disturbed behavior should be included; however, this was not the case in $29 \%$ of these 21 codes. Further, it is problematic to define 
disturbance only by looking at behavioral changes (Orams, 2004). Internal reactions, such as increased levels of stress hormones, do not necessarily show as physical signs of distress (e.g. Creel et al., 2002) and disturbance does not always cause pinnipeds to change their behavior in obvious ways. The response can also be dependent on the behavior and state of the animals prior to disturbance. Numerous studies have shown that the pinnipeds are more reluctant to leave the haul out site and enter the water during some periods of their life, such as breeding, molting, and nursing. Hence, the animals could be more sensitive to disturbance during these periods (Andersen et al., 2012; Cunningham et al., 2009; Henry \& Hammill, 2001). Boren et al., (2002) show that New Zealand fur seals (Arctocephalus pusillus doriferus) are most sensitive to disturbance during the breeding season, and French et al. (2011) conclude that increased human disturbance leads to reduced reproductive output for Californian sea lions (Zalophus californianus) in breeding areas. The need for tourists to take extra caution during these seasons was mentioned in a majority of the codes (Figure 3); however, these codes should also define exactly when sensitive events occur since this might not be apparent to tourists.

Feeding and touching animals were not encouraged in any of the codes (Figure 4) and many strictly prohibited these practices. Although not commonly used with pinniped tourism, feeding is used in many locations to attract other wildlife (e.g., Knight, 2010; Maljkovic \& Côte, 2011) and remains a debated issue in wildlife tourism (Newsome \& Rodger, 2008; Orams, 2002). Feeding wild animals can have implications on behavior and fitness of animals and be dangerous to humans, and should therefore be discouraged if not strictly controlled (Burns \& Howard, 2003; Clua et al., 2010; Semeniuk \& Rothley, 2008; Smith et al., 2008).

Studies on swimming with pinnipeds in Australia and New Zealand show that fur seal behavior is affected by the presence of swimmers and strict management is required for this activity to be sustainable (Boren et al., 2008; Cowling et al., 2014; Stafford-Bell, 2012). Information on swimming with pinnipeds was lacking in some codes, although when it was discussed it was often discouraged. Low water temperatures making swimming unpopular in some locations, such as Iceland, could, in part, explain the lack of information. 
Noise reduction was mentioned in a majority of the codes (Figure 4) and loud noise has been shown to elicit stronger reactions in animals (Tripovich et al., 2012). Some human behavioral factors, such as body language, are more difficult to control or standardize but noise is easy to reduce for boats and individuals. Prohibiting feeding and touching of pinnipeds and noise reduction are universal factors that minimize disturbance to pinnipeds and can be applied to all species and locations.

\section{An international code of conduct for pinniped watching}

This investigation of codes of conduct for pinniped watching discovered a great variety between different codes worldwide, which is not favorable in terms of reaching the goal of sustainable pinniped tourism. We suggest a development of an internationally recognized code of conduct that unifies all the various codes for pinniped watching identified in this study, to increase proteetion of these species. Likewise, developing an international code of conduct for whale watching is recommended by Garrod and Fennel (2004). However, they argue "there is so little common ground among the many [whale watching] codes that any hope of international harmonization could be viewed as being wildly optimistic" (Garrod \& Fennel, 2004, p. 349). To increase the possibilities for successful development of an international pinniped watching code of conduct, we encourage a "triple helix" approach, involving governmental agencies, tour operators and scientists in the process of creating codes of conduct for specific areas and species (Granquist \& Nilsson 2016). The Pinniped Specialist Group (seals and walruses) within IUCN (International Union for Conservation of Nature) could be a feasible coordinator of discussions and aims when creating an international pinniped watching code of conduct. We underline three important aspects that should be taken into consideration during the development of such guidelines; scientific foundation, interdisciplinary cooperation, and local and species specific additions. Firstly, building codes of conduct based on research and academic findings is crucial. As mentioned above, one reason for the variation between the codes of today might be the lack of knowledge, either generally on how marine mammals are affected by tourism on a large scale, or in some cases species specific knowledge. Indeed, further research is needed to tie different disturbance levels to specific response variables and in some cases a deeper knowledge regarding possible 
extra sensitivity during important periods, such as the breeding or molting period, is lacking. Nevertheless, an international code of conduct based on existing knowledge of factors proven to affect the welfare of wild pinnipeds could provide consistent measures for protecting the world's seal species and contribute to sustainable tourism activities. Since the scientific background is general for many species, the motivation behind several guidelines can also be general and in that case such motivation can also be summarized in an international code of conduct.

Secondly, for an international code to be applicable, and take into account all the important factors governing pinniped watching, it should be developed in discipline independent collaboration between government, entrepreneurs within the tourism industry, conservation scientists and tourism researchers. Interdisciplinary collaboration is likely to be fruitful when it comes to transferring and implementing knowledge obtained from academic research into the society (Granquist \& Nilsson, 2013; Granquist \& Nilsson, 2016).

Thirdly, although the general aim for an international code should be universal guidelines applicable to all pinniped species it might be desirable to include some species specific and/or local adjustments in the international code. Based on the findings from this study, Table 2 lists factors that should be considered in an international pinniped watching code of conduct. General factors that apply for all areas of the world and for all pinniped species include explanations of and recommendations regarding not feeding, touching or following pinnipeds at sea or on land, as well as minimizing noise and behaving calmly in general. Other factors may vary depending on topography and geography as well as the species considered and hence might demand specific adaptions in the code. The topography of the site affects the likelihood of seals being disturbed, such as how visible the visitors are to the seals, as well as how close visitors can get to the pinnipeds. Further, the time of year when sensitive periods occur, such as breeding or molting, differ between species and populations and can even vary regionally (Bigg, 1969; Temte et al., 1991). Australian sea lions, for example, do not have an annual cycle and their breeding seasons are asynchronous (Shaughnessy et al. 2011). Consequently, these species specific local adjustments should be included in an international code. 
Sensitivity to factors initiating antipredator responses among pinnipeds is likely to be species specific. For example, the flush distance of pinnipeds is likely to differ between species and hence affects the minimum approach distance. Further, in many codes investigated in this paper, visitors are recommended to self-evaluate if the seals are disturbed and take appropriate action if required. Thus, since some behavior that indicates disturbance among pinnipeds varies between species, a species-specific description of known behaviour indicators for disturbance is neccessary (Table 2). If species are endangered, extra local additions to the code might be needed and, in some cases, specific cultural considerations should also be included.

Further, the code should be fully explanatory to increase compliance and add educational value to the wildlife tourism experience. Such a code could aid in protecting pinnipeds worldwide, enhancing wildlife encounters for tourists and contribute to implementing sustainable businesses for tour operators.

\section{Table 2 here.}

\section{Conclusion}

Owing to the popularity of pinnipeds as objects of wildlife tourism (Burns, 2015b), codes of conduct developed to incorporate both the welfare of wild pinnipeds and the best interest of tourists and the tourism industry are needed. Such codes should be based on research that considers how to best minimize negative impacts on pinnipeds due to wildlife tourism.

Almost half of the codes examined were general for marine wildlife or mammals (with specific additions for pinnipeds) and only $12 \%$ were species specific. The importance of developing codes specifically for pinnipeds becomes evident when taking factors such as behavior, seasons and distribution into consideration. Codes of conduct for marine mammals are generally focused on cetaceans; however, cetaceans and pinnipeds have extremely different behavior and life cycles. A general code for marine wildlife or marine mammals might work under some circumstances, but for improved protection of pinnipeds, codes need to encompass factors specific to these animals. Since pinnipeds are marine mammals with connection to land it is important that codes of conduct consider both boat and land-based approaches as well as an explanation of 
why caution should be taken during sensitive periods when pinnipeds are often hauled out on land. In addition, descriptions of behavior for specific species of pinnipeds should be included and mentioned as a factor to be aware of, since agitated pinnipeds could cause harm to themselves, other animals and humans. Information on pinniped behavior should preferably be based on species-specific research.

We claim that an international pinniped code of conduct built on research and developed through interdisciplinary cooperation would contribute to sustainable pinniped watching. As suggested, some local and species specific additions might be beneficial; however, an international code would provide a quicker implementation for newly established pinniped tourism areas and provide the best possible protection even where extensive local research has not yet been conducted.

\section{Acknowledgements}

This study was part of The Wild North project, and the Ekoklim project at Stockholm University.

\section{Bibliographical notes}

Elin Lilja Öqvist's master's degree in marine biology from Stockholm University included an interdisciplinary study focused on the knowledge and opinions of tourists connected to hunting and tourism of marine mammals. Elin currently works as a whalewatching guide in Norway and her research interests focus on the interactions between tourism and marine mammals.

Sandra M. Granquist is Head of Seal Research at the Icelandic Seal Center in Hvammstangi and a seal specialist at the Marine and Freshwater Research Institute of Iceland. She holds a PhD in behavioral ecology from Stockholm University. Sandra's main research interest is interactions between wildlife and tourism, such as how tourism affects animal behavior and ecology and she also studies interdisciplinary management of wildlife.

Georgette Leah Burns is a senior lecturer at Griffith University and foundation member of the Environmental Futures Research Institute. She holds an adjunct position as Associate Professor in the Rural Tourism Department at Hólar University College. With a $\mathrm{PhD}$ in Tourism from Murdoch University, she blends theory and methods from 
anthropology and environmental science to understand the interactions between humans and wildlife in nature based tourism settings.

Anders Angerbjörn is a professor and chair in ecology in the Zoological Department at Stockholm University in Sweden. His research focuses on Arctic and subarctic ecology, often with a conservation biology perspective. This work incorporates the study of dolphins, porpoises and seals, as well as studies of predator and prey populations focusing on carnivores in mountain regions such as arctic foxes, gyrfalcon, golden eagle, rough-legged buzzard, and wolverine.

\section{References}

Andersen S.M., Teilmann J., Dietz R., Schmidt N.M., Miller L.A. (2012). Behavioural responses of harbour seals to human-induced disturbances. Aquatic Conservation: Marine and Freshwater Ecosystems 22: 113-121.

Ballantyne R., Packer J., Hughes K. (2009). Tourists support for conservation messages and sustainable management practices in wildlife tourism experiences. Tourism Management 30: 658-664.

Ballantyne R., Packer J., Sutherland L.A. (2011). Visitors' memories of wildlife tourism: Implications for the design of powerful interpretive experiences. Tourism Management 32: 770-779.

Bejder L., Samuels A., Whitehead H., Gales N. (2006). Interpreting short-term behavioural responses to disturbance within a longitudinal perspective. Animal Behaviour 72: 1149-1158.

Bigg, M. (1969). Clines in the pupping season of the harbour seal, Phoca vitulina. Journal of the Fisheries Research Board of Canada 26: 449-455.

Boren L.J., Gemmell N., Barton K. (2008). The role and presence of a guide: preliminary findings from swim with seal programs and land-based seal viewing in New Zealand. Tourism in Marine Environments 5: 187-199.

Boren L.J., Gemmell N.J., Barton K.J. (2002). Tourist disturbance on New Zealand fur seals. Australian Mammalogy 24: 85-95.

Borkowski J.J., White P.J., Garrott R.A., Davis T., Hardy A.R., Reinhart D.J. (2006). Behavioral responses of bison and elk in Yellowstone to snowmobile and snow coaches. Ecological Applications 16: 1911-1925. 
Burns G.L. (2004) The Host Community and Wildlife Tourism. In Karen Higginbottom (ed), In Wildlife Tourism: Impacts, management and Planning (pp. 125-144). Gold Coast: Common Ground Publishing.

Burns G.L. (2015a). Ethics in Tourism. In C.M. Hall, S. Gossling and D. Scott (eds), The Routledge Handbook of Tourism and Sustainability (pp. 117-126). New York: Routledge.

Burns G.L. (2015b). Animals as Tourism Objects: Ethically refocusing relationships between tourists and wildlife. In K. Markwell (ed), Animals and Tourism: Understanding Diverse Relationships (pp. 44-59). Bristol: Channel View Publications.

Burns G.L., Howard P. (2003). When wildlife tourism goes wrong: a case study of stakeholder and management issues regarding Dingoes on Fraser Island, Australia. Tourism Management 24: 699-712.

Burns G.L., Moore S., Macbeth J. (2011). Should dingoes die ? Principles for engaging ecocentric ethics in wildlife tourism management. Journal of Ecotourism 10: 179196.

Carlson C. (2001). A review of whale watch guidelines and regulations around the world: Version 2001. International Whaling Commission, Princetown, MA.

Cassini M.H. (2001). Behavioural responses of South American fur seals to approach by tourists - a brief report. Applied Animal Behaviour Science 71: 341-346.

Cater C. (2010) Any closer and you'd be lunch!: Interspecies interactions as nature tourism at marine aquaria. Journal of Ecotourism 9 (2), 133-148.

Christiansen F., Rasmussen M., Lusseau D. (2013a). Whale watching disrupts feeding activities of minke whales on a feeding ground. Marine Ecology Progress Series 478: 239-251.

Christiansen F., Rasmussen M.H., Lusseau D. (2013b). Inferring activity budgets in wild animals to estimate the consequences of disturbances. Behavioral Ecology 24: $1415-1425$.

Clua E., Buray N., Legendre P., Mourier J., Planes S. (2010). Behavioural response of sicklefin lemon sharks Negaprion acutidens to underwater feeding for ecotourism purposes. Marine Ecology Progress Series 414: 257-266. 
Cole S. (2007). Implementing and evaluating a code of conduct for visitors. Tourism Management 28: 443-451.

Cong L., Wu B., Morrison A.M., Shu H., Wang M. (2014). Analysis of wildlife tourism experiences with endangered species: An exploratory study of encounters with giant pandas in Chengdu, China. Tourism Management 40: 300-310.

Cowling M., Kirkwood R., Boren L.J., Scarpaci C. (2014). The effects of seal-swim activities on the New Zealand fur seal (Arctophoca australis forsteri) in the Bay of Plenty, New Zealand, and recommendations for a sustainable tourism industry. Marine Policy 45: 39-44.

Creel S., Fox J.E., Hardy A., Sands J., Garrott B., Peterson R.O. (2002). Snowmobile activity and glucocorticoid stress responses in wolves and elk. Conservation Biology 16: 809-814.

Cunningham L., Baxter J.M., Boyd I.L., Duck C.D., Lonergan M., Moss S.E., McConnell, B. (2009). Harbour seal movements and haul-out patterns: implications for monitoring and management. Aquatic Conservation: Marine and Freshwater Ecosystems, 19(4): 398-407.

Curtin S. (2009). Wildlife tourism: the intangible, psychological benefits of humanwildlife encounters. Current Issues in Tourism 12: 451-474.

Davenport J., Davenport J.L. (2006). The impact of tourism and personal leisure transport on coastal environments: A review. Estuarine, Coastal and Shelf Science 67: 280-292.

Dobson J., (2008). Shark! A new frontier in tourist demand for marine wildlife. In: Higham J., Lück M. (Eds.), Marine wildlife and Tourism Management: Insights from the Natural and Social Sciences (pp. 49-65.). CABI, Oxfordshire.

Donaldson R., Finn H., Calver M. (2010) Illegal Feeding Increases Risk of Boat-strike and Entanglement in Bottlenose Dolphins in Perth, Western Australia. Pacific Conversation Biology 16(3): 157-161.

Duprey N.M.T., Weir J.S., Würsig B. (2008). Effectiveness of a voluntary code of conduct in reducing vessel traffic around dolphins. Ocean \& Coastal Management 51: 632-637.

Ellenberg U., Setiawan A.N., Cree A., Houston D.M., Seddon P.J. (2007). Elevated hormonal stress response and reduced reproductive output in Yellow-eyed 
penguins exposed to unregulated tourism. General and comparative endocrinology 152: 54-63.

Fennell D. (2012). Tourism and Animal Ethics. New York: Routledge.

Fitzpatrick R., Abrantes K.G., Seymour J., Barnett A. (2011). Variation in depth of whitetip reef sharks: does provisioning ecotourism change their behavior? Coral Reefs 30: 569-577.

French S.S., González-Suárez M., Young J.K., Durham S., Gerber L.R. (2011). Human disturbance influences reproductive success and growth rate in California sea lions (Zalophus californianus). PloS one 6: e17686.

Garrod B., Fennell D.A. (2004). An analysis of whale watching codes of conduct. Annals of Tourism Research 31: 334-352.

Granquist S.M., Nilsson P.A. (2013). The wild north: Network cooperation for sustainable tourism in a fragile marine environment in the Arctic region. In Müller DK, Lundmark L, Lemelin RH (eds), New Issues in Polar Tourism,(pp. 123-132). Springer Netherlands: Dordrecht.

Granquist S.M., Nilsson P.A. (2016). Who's watching whom? -An interdisciplinary approach to studying seal watching tourism in Iceland. Journal of Cleaner Production, 111: 471-478.

Granquist S.M., Sigurjonsdottir H. (2014). The effect of land based seal watching tourism on the haul-out behaviour of harbour seals (Phoca vitulina) in Iceland. Applied Animal Behaviour Science 156; 85-93.

Gössling S. (1999). Ecotourism: a means to safeguard biodiversity and ecosystem functions? Ecological Economics 29: 303-320.

Henry E., Hammill M.O. (2001). Impact of small boats on the haulout activity of harbour seals (Phoca vitulina) in Métis Bay, Saint Lawrence Estuary, Québec, Canada. Aquatic mammals 27: 140-148.

Higginbottom K. and Tribe A. (2004). Contributions of wildlife tourism to conservation. In Higginbottom, K (ed). Wildlife tourism: Impacts, management and planning (pp. 99-124). Common Ground Publishing: Altona.

Hoover-Miller A., Bishop A., Prewitt J., Conlon S., Jezierski C. and Armato P. (2013). Efficacy of voluntary mitigation in reducing harbor seal disturbance. The Journal of Wildlife Management, 77: 689-700. 
Jansen J.K., Boveng P.L., Dahle S.P., Bengtson J.L., (2010). Reaction of harbor seals to cruise ships. The Journal of Wildlife Management, 74: 1186-1194.

Johnson A., Acevedo-Gutiérrez A. (2007). Regulation compliance by vessels and disturbance of harbour seals (Phoca vitulina). Canadian Journal of Zoology 85: 290-294.

King J.M., Heinen J.T. (2004). An assessment of the behaviors of overwintering manatees as influenced by interactions with tourists at two sites in central Florida. Biological Conservation 117: 227-234.

Kirkwood R., Boren L., Shaughnessy P., Mawson P., Hückstädt L., Hofmeyr G., Oosthuizen H., Schiavini A., Berris M. (2003). Pinniped-focused tourism in the southern hemisphere: A review of the industry. In Gales N., Hindell M., Kirkwood P. (eds), Marine mammals and humans: Fisheries, tourism and management issues (pp. 257-276). CSIRO Publishing: Melbourne.

Knight J. (2010). The ready-to-view wild monkey: The convenience principle in Japanese wildlife tourism. Annals of Tourism Research 37: 744-762

Kovacs K.M., Innes S. (1990). The impact of tourism on harp seals (Phoca groenlandica) in the Gulf of St. Lawrence, Canada. Applied Animal Behaviour Science 26: 15-26.

Kowalewsky S., Dambach M., Mauck B., Dehnhardt G. (2006). High olfactory sensitivity for dimethyl sulphide in harbour seals. Biological Letters 2: 106-109.

Le Boeuf B.J., Campagna C. (2013). Wildlife viewing spectacles: best practices from elephant seal (Mirounga sp.) colonies. Aquatic Mammals 39: 132-146.

Lemelin R.H., Dyck M., (2008). New frontiers in marine wildlife tourism: an international overview of polar bear tourism management strategies. In: Higham, J.E.S., Luick, M. (Eds.), Marine Wildlife and Tourism Management: Insights from the Natural and Social Sciences (pp. 361-379). CABI, Oxfordshire.

Lindsey P.A., Havemann C.P., Lines R.M., Price A.E., Retief T.A., Rhebergen T., Van der Waal C., Romañach S.S. (2013). Benefits of wildlife-based land uses on private lands in Namibia and limitations affecting their development. Oryx 47: 4153. 
Lindsey P.A., Alexander R.R., du Toit J.T., Mills M.G.L. (2005). The potential contribution of ecotourism to African wild dog Lycaon pictus conservation in South Africa. Biological Conservation 123: 339-348.

Lovelock B., Lovelock K.M. (2013). The Ethics of Tourism: Critical and applied perspectives. Routledge: New York.

Lundquist D., Gemmell N.J., Würsig B., Markowitz T. (2013). Dusky dolphin movement patterns: short-term effects of tourism. New Zealand Journal of Marine and Freshwater Research 47: 430-449.

Lusseau D. (2006). The short-term behavioral reactions of bottlenose dolphins to interactions with boats in Doubtful Sound, New Zealand. Marine Mammal Science 22: $802-818$.

Lück M. (2003). Education on marine mammal tours as agent for conservation-but do tourists want to be educated? Ocean \& Coastal Management 46: 943-956.

Maljkovic A., Côte I. (2011) Effects of tourism-related provisioning on the trophic signatures and movement of patterns of an apex predator, the Caribbean reef shark. Biological Conservation 144: 859-865.

Mason P., Mowforth M. (1996). Codes of conduct in tourism. Progress in Tourism and Hospitality Research 2: 151-167.

Mattlin R.H. (1978). Pup mortality of the New Zealand Fur seal (Arctocephalus forsteri lesson). New Zealand Journal of Ecology 1: 138-144.

Moore S.A., Rodger K. (2010). Wildlife tourism as a common pool resource issue: enabling conditions for sustainability governance. Journal of Sustainable Tourism 18: $831-844$.

Müllner A., Eduard Linsenmair K., Wikelski M. (2004). Exposure to ecotourism reduces survival and affects stress response in hoatzin chicks (Opisthocomus hoazin). Biological Conservation 118: 549-558.

Newsome D., Rodger K. (2008). To feed or not to feed: a contentious issue in wildlife tourism. In Lunney, D., Munn, A., Meikle, W. (Eds.), Too Close for Comfort: Contentious Issues in Human-Wildlife Encounters (pp. 255-270). Royal Zoological Society of New South Wales, Mosman,

Newsome D., Dowling R., Moore S. (2005). Wildlife Tourism. Channel View Publications: Clevedon. 
Orams M.B. (1997). The effectiveness of environmental education: can we turn tourists into "greenies'? Progress in Tourism and Hospitality Research 3: 295-306.

Orams M.B. (2002). Feeding wildlife as a tourism attraction: a review of issues and impacts. Tourism Management 23: 281-293.

Orams M. (2004). Why Dolphins May Get Ulcers: Considering the impacts of cetaceanbased tourism in New Zealand. Tourism in Marine Environments 1: 17-28.

Orsini J.P., Shaughnessy P.D., Newsome D., (2006). Impacts of human visitors on Australian Sea Lions (Neophoca cinerea) at Carnac Island, Western Australia: implications for tourism management. Tourism Marine Environ. 3, 101-115.

Osano P.M, Said M.Y, de Leeuw J., Ndiwa N., Kaelo D., Schomers S., Birner R., Ogutu J.O. (2013). Why keep lions instead of livestock? Assessing wildlife tourism-based payment for ecosystem services involving herders in the Maasai Mara, Kenya. Natural Resources Forum 37: 242-256.

Osinga N., Nussbaum S.B, Brakefield P.M, Udo de Haes H.A. (2012). Response of common seals (Phoca vitulina) to human disturbances in the Dollard estuary of the Wadden Sea. Mammalian Biology 77: 281-287.

Quiros A.L. (2007). Tourist compliance to a Code of conduct and the resulting effects on whale shark (Rhincodon typus) behavior in Donsol, Philippines. Fisheries Research 84: 102-108.

Patrick P.G., Tunnicliffe S.D. (2013). Zoo Talk. Dordrecht: Springer.

Sekhar N.U. (2003), Local people's attitudes towards conservation and wildlife tourism around Sariska Tiger Reserve, India. Journal of Environmental Management 69: $339-47$

Semeniuk C.A.D., Rothley K.D. (2008). Costs of group-living for a normally solitary forager: effects of provisioning tourism on southern stingrays Dasyatis americana. Marine Ecology Progress Series 357: 271-282.

Semeniuk C.A.D., Rothley K.D. (2009). Hematological differences between stingrays at tourist and non-visited sites suggest physiological costs of wildlife tourism. Biological Conservation 142: 1818-1829.

Shaughnessy P.D., Nicholls A.O. Briggs, S.V. (2008). Do tour boats affect fur seals at Montague Island, New South Wales? Tourism in Marine Environments 5: 15-27. 
Shaughnessy P.D., Goldsworthy S.D., Hamer D.J., Page B., McIntosh R.R. (2011). Australian sea lions Neophoca cinerea at colonies in South Australia: distribution and abundance, 2004 to 2008. Endangered Species Research 13: 87-98.

Sirakaya E. (1997). Attitudinal compliance with ecotourism guidelines. Annals of Tourism Research 24: 919-950.

Smith H., Samuels A., Bradley S. (2008). Reducing risky interactions between tourists and free-ranging dolphins (Tursiops sp.) in an artificial feeding program at Monkey Mia, Western Australia. Tourism Management 29: 994-1001.

Stafford-Bell R. (2012). Behavioural Responses of the Australian Fur Seal (Arctocephalus pusillus doriferus) to Vessel Traffic and Presence of Swimmers in Port Phillip Bay, Victoria, Australia. Aquatic Mammals 38: 241-249.

Strong P., Morris S.R. (2010) Grey seal (Halichoerus grypus) disturbance, ecotourism and the Pembrokeshire Marine Code around Ramsey Island.

Journal of Ecotourism 9: 117-132

Temte J.L., Bigg M.A., Wiig Ø. (1991). Clines revisited: The timing of pupping in the harbour seal (Phoca vitulina). Journal of Zoology 224: 617-632.

Tripovich J.S., Hall-Aspland S., Charrier I., Arnould J.P.Y. (2012). The behavioural response of Australian fur seals to motor boat noise. PloS one 7: e37228.

Valentine P.S., Birtles A., Curnock M., Arnold P., Dunstan A. (2004). Getting closer to whales-passenger expectations and experiences, and the management of swim with dwarf minke whale interactions in the Great Barrier Reef. Tourism Management 25: 647-655.

Ziegler J., Dearden P., Rollins R. (2012). But are tourists satisfied? Importanceperformance analysis of the whale shark tourism industry on Isla Holbox, Mexico. 
Copyright @ 2017 Cognizant Communication Corporation

\section{Figure and Table Legends}

Table 1. Factors used for analysis of codes of conduct for pinniped watching globally

Table 2. Factors that should be included in an international pinniped watching code.

Figure 1. Percentage of different minimum distance recommendations for boat- based $(\mathrm{n}=27)$ and land- based $(\mathrm{n}=22)$ watching of pinnipeds.

Figure 2. Percentage of codes with recommendations for time limits and the distribution among different time intervals for boat- based $(n=27)$ and land- based $(n=22)$ codes of conduct.

Figure 3. Percentage of codes with and without special recommendations on sensitive seasons or sensitive areas $(n=33)$.

Figure 4. Percentage of codes with recommendations considering feeding, touching or swimming with pinnipeds and recommendations for reducing noise levels. 
Copyright @ 2017 Cognizant Communication Corporation

\section{Tables and Figures}

Table 1. Factors used for analysis of codes of conduct for pinniped watching globally

\section{Factors considering the setting and information about the codes of conduct}

Region Continent where code is in use

Developed by

Research based

Enforcement

Species of focus

Target group of the code

Boat/land-based watching

Presentation of code
Governments, Non-governmental organizations or the industry

If the code is based on research on conservation

Entirely regulatory (based on laws), partly regulatory or not stated

Marine wildlife, marine mammals, pinnipeds or specific species of pinnipeds

The general public, tourists specifically, tour operators or both tour operators and tourists

If the code is developed for boat-based or land-based watching of pinnipeds, or both

Non-explanatory or explanatory

\begin{tabular}{ll}
\hline Factors considered for analysis of the content of codes of conduct \\
\hline Minimum distances & $\begin{array}{l}\text { Minimum distance recommended for viewing by boat } \\
\text { or on land } \\
\text { Maximum time recommended with animals }\end{array}$ \\
\hline $\begin{array}{l}\text { Time limitation } \\
\text { recommendations }\end{array}$ & $\begin{array}{l}\text { Restrictions for swimming, feeding, touching or noise } \\
\begin{array}{l}\text { Awareness of disturbed } \\
\text { behavior }\end{array}\end{array}$ \\
$\begin{array}{l}\text { Recommendations on how to behave if signs of } \\
\text { disturbance are shown by the pinnipeds }\end{array}$ \\
\hline
\end{tabular}


Copyright @ 2017 Cognizant Communication Corporation

Table 2. Factors that should be included in an international pinniped watching code of conduct.

\section{Factors}

1. Sensivitve periods I, II

2. Sensivitve areas I,II

3. Time spent near pinniped colony

4. Number of visits to pinniped colony

5. Visitor group size

6. Distance between pinniped colony and boat/individual visitor ${ }^{\mathrm{I}}$

7. Boat speed

7. Sound level (boat engine and/or voice level)

8. General visitor behaviour

9. Pinniped behaviour indicating disturbance II

10. Avoid blocking water access of pinnipeds

11. Avoid following pinnipeds

12. Avoid feeding pinnipeds

13. Avoid touching pinnipeds

I) Site specific considerations should be done

II) Species specific considerations should be done 


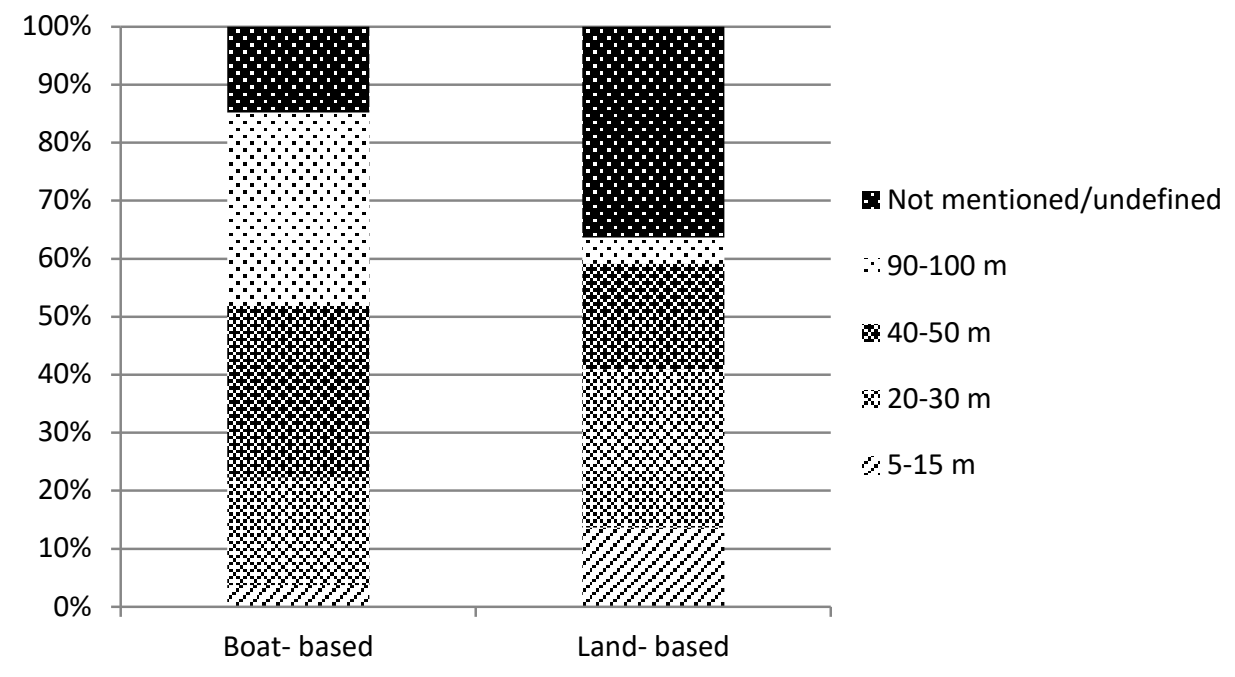

Figure 1. Percentage of different minimum distance recommendations for boat- based $(n=27)$ and land- based $(n=22)$ watching of pinnipeds.

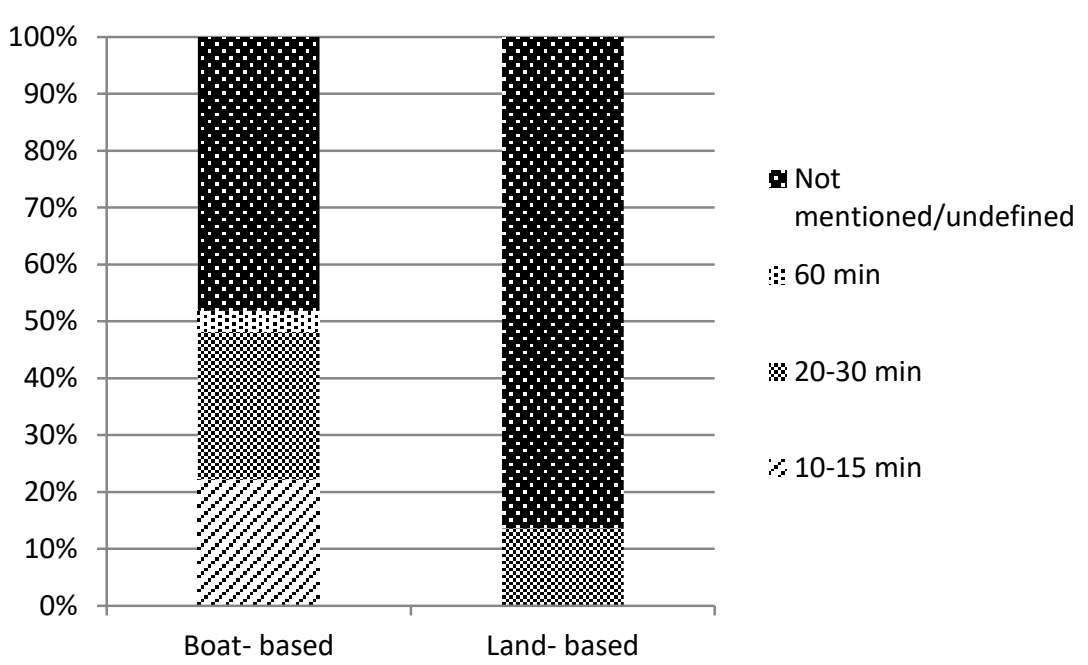

Figure 2. Percentage of codes with recommendations for time limits and the distribution among different time intervals for boat- based $(n=27)$ and land- based $(n=22)$ codes of conduct. 


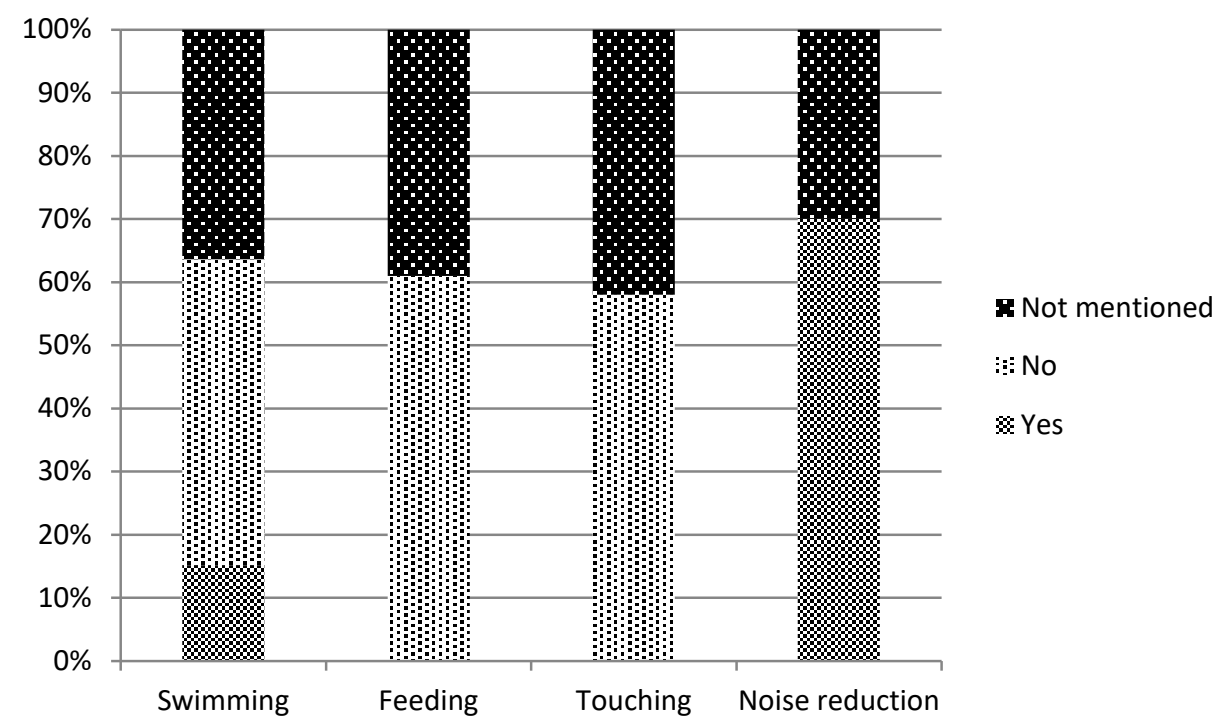

Figure 3. Percentage of codes with recommendations considering feeding, touching or swimming with pinnipeds and recommendations for reducing noise levels.

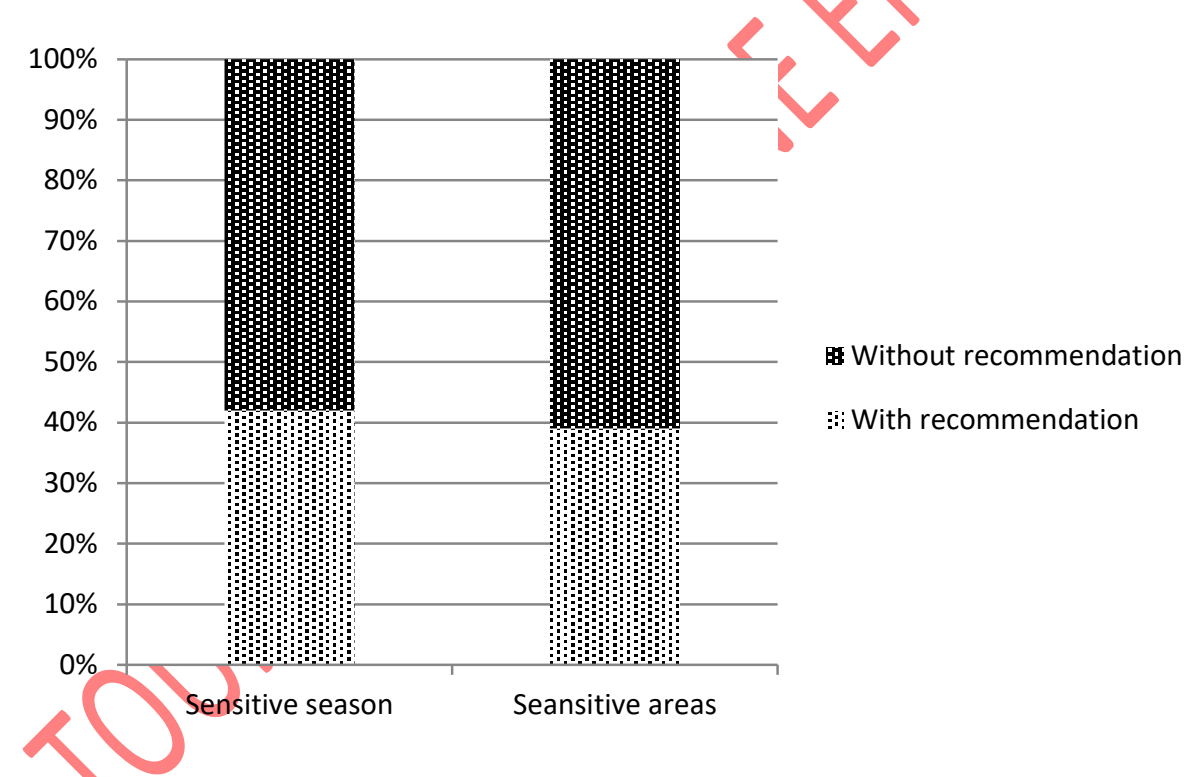

Figure 4. Percentage of codes with and without special recommendations on sensitive seasons or sensitive areas $(n=33)$. 